\title{
O Mecanismo da Função de Produção: a Análi- se dos Sistemas Produtivos do Ponto-de-Vista de uma Rede de Processos e Operações
}

\author{
José Antônio Valle Antunes Jr. \\ Mestre em Engenharia de Produção - UFSC \\ Universidade Federal do Rio Grande do Sul \\ Programa de Pós-Graduação em Engenharia de Produção \\ Praça Argentina $\mathbf{s} / \mathbf{n}$ \\ CEP 90040-020 - Porto Alegre - RS
}

Palavras Chaves : Gerência de Produção, Sistema Toyota, Mecanismo Função de Produção

Key-words : Production and Operations Management, Toyota System, Mechanism of the Production Function

\section{RESUMO}

Muitos artigos têm sido escritos e muitos debates têm sido realizados no mundo ocidental, versando sobre a problemática do Sistema Toyota de Produção, tando do ponto-de-vista macoeconómico do desenvolvimento das cadeias produtivas, como do ponto-de-vista mais estrito da Engenharia Industrial.

Porém, o que se percebe, na maioria das vezes, é a simplificação do Sistema Toyota de Produção, ora tratando-o como sinônimo da idéia do Just-in-Time, ora tratando-o como sinônimo da idéia do JustIn-Time/controle da Qualidade Total, passando a idéia de que é perfeitamente possível adaptar com facilidade o JIT, ou o "modelo japonês de gestão", ao ocidente.

No nosso ponto-de-vista, a realidade é bem outra, e o que se passa é que os gerentes ocidentais estāo experimentando algumas características do Sistema Toyota de Produção, tais como, por exemplo, o Kanban e o JIT, sem compreender em profundidade as raizes conceituais do sistema Toyota de Produção e suas implicaçōes em amplos campos do conhecimento industrial.

O objetivo central deste trabalho consiste em discutir criticamente um método de análise para compreensão de sistemas produtivos proposto por Shigeo Shingo; o Mecanismo da Função de Produção.

\section{ABSTRACT}

Different papers have been presented and many discussions have been realized concerning about the Toyota Production System, from a macroeconomics point of view as well from an Industrial Engineering point of view.

The problem is, that most of the time what is shown is a narrow understanding of the Toyota System, which is seen as a simple synonymy of Just-in-Time or Just-in-Time/ Total Quality Control. As a result, it seems that the Toyota System can be easily implemented in western companies.

In fact, what happens is that western managers do not understand deeply the main concepts behind the Toyota System and its relationship with wide fields of Industrial knowledge. The main purpose of this paper is to present critically an analysis for the understanding of Production Systems, proposed by Shigeo Shingo : the Mechanism of the Production Function. 


\section{O Mecanismo da Função de Produção: uma Rede de Processos e Operações}

\author{
"Todas as produçōes podem ser com- \\ preendidas como uma rede funcional \\ de processo e operações! Naturalmen- \\ te, o Sistema Toyota de Produçāo não \\ é uma exceçåon" (Shigeo Shingo).
}

O ponto de partida para a apresentação do Mecanismo da Função de Produção é a diferenciação entre as funçōes Processo e Operação. Existem basicamente duas óticas básicas que permitem a observação e análise dos fenômenos que ocorrem na produção, seja ela industrial ou de serviços: observar o fluxo do objeto de trabalho (material) no tempo e no espaço e observar o fluxo do sujeito de trabalho (homens-trabalho vivo, e máquinas e equipamentos-trabalho morto) no tempo e no espaço. É a partir destas duas óticas de visualização que surgem os conceitos de processo e operação.

Processo refere-se ao fluxo de materiais ou produtos de um trabalhador para outros, nos diferentes estágios nos quais pode-se observar a transformação gradativa das matérias-primas e produtos acabados. Ou ainda, os processos podem ser simplesmente definidos como: "o fluxo de materiais para os produtos, que modifica-se de acordo com o curso simultâneo do tempo e do espaço" (SHINGO, 1981)

Operação refere-se à análise dos diferentes estágios, no qual os trabalhadores podem estar trabalhando em diferentes produtos, ou seja, representa uma análise do comportamento humano na produção, no tempo e no espaço.

Como obviamente as pessoas utilizam-se de máquinas, equipamentos, ferramentas etc..., para trabalharem, pode-se dizer mais amplamente que o fluxo do sujeito do trabalho não consiste somente das pessoas (trabalho vivo) mas, também, dos equipamentos e ferramentas (trabalho morto) para a execução dos procedimentos operativos no tempo e no espaço.

Shingo (SHINGO, 1986) define sinteticamente operação como sendo: "Operadores e máquinas (que são assistentes dos homens) que modifica-se de acordo com o curso simultâneo do tempo e do espaço".

No caso de análise da operação, a ótica de observação é distinta do processo. Assim, por exemplo: um trabalhador retira um material $\mathrm{A}$ do almoxarifado de matéria-prima até uma dada máquina $A$, posteriormente descansa um certo tempo depois, transporta um material $B$ até a máquina $A$, vai ao lavatório, posteriormente leva um material $\mathrm{C}$ do almoxarifado até a máquina $A$, etc... esta seria uma típica análise da operação.

Os estudos originais que enfocam a lógica da operação foram historicamente desenvolvidos a partir de Gilbreth, que analisou o estudo dos movimentos e Taylor, que efetivou o estudo dos tempos.

A lógica de visualização do Mecanismo da Função de Produção, descoberta e proposta originalmente no ano de 1945 por Shigeo Shingo, consiste em visualizar os sistemas produtivos a partir da lógica de uma rede que envolve nos eixos $\mathrm{X}$ e $\mathrm{Y}$ os processoe e as operaçōes.

Ou seja, os sistemas produtivos são visualizados a partir de uma combinação do acompanhamento dos fluxos de materiais no tempo e no espaço e do acompanhamento do fluxo de pessoas e equipamentos, dispositivos, etc... no tempo e no espaço.

Portanto, cada nó da rede corresponde a um encontro da lógica dos processos e das operações. Por exemplo, em um dado nó da rede pode-se ter inspeção. Neste caso, em um dado tempo e espaço, encontrar-se-ão reunidos o objeto e os sujeitos da produção: materiais, pessoas e equipamentos de inspeção.

\footnotetext{
${ }^{1}$ Este conceito não foi originalmente proposto por Shigeo Shingo. Sua criaçāo deve-se a F.B.Gilbreth, que no ano de 1921 postulou para o "Journal of the Amnerican Society of the Mechanical Engineering", que os fenómenos relacionados com a produção, incluiam o fluxo que levava as matérias primas aos produtos acabados e que, além disso, os processos eram compostos basicamente por 4 fenômenos distintos e universais: processamento (fabricação), inspeção, transporte e espera.
} 
Observa-se também, que em outros pontos localizados no tempo e no espaço não existirá a interseção do objeto e dos sujeitos da produção. Por exemplo, uma análise para um certo tempo e espaço específica poderá identificar que um lote de material está esperando para ser processado (análise do processo) enquanto as pessoas estão executanto uma preparação de uma certa máquina para oa processamento deste mesmo lote (análise de operação).

Como exemplo das discussões acima, uma síntese didática da ótica da estrutura de produção vista como uma rede entre os processos e operaçōes, é apresentado por Shingo na figura a seguir.

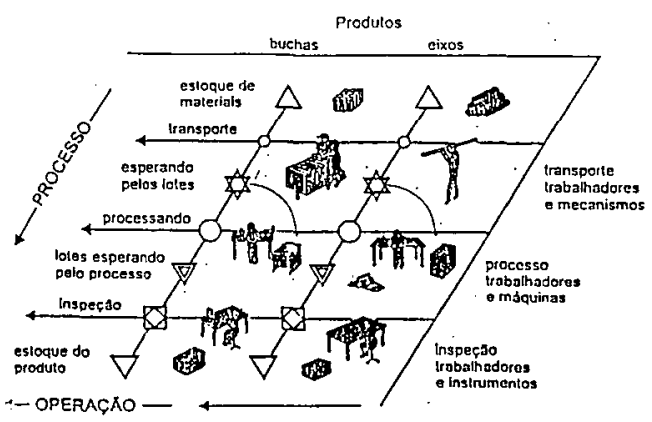

FIGURA 1 - Estrutura de Produção: Uma rede de Processos e Operações Retirado das Obras de Shigeo Shingo.

Um processo é um fluxo integrado de materiais no qual irão aparecer pessoas e máquinas; por exemplo, trabalhadores de transporte, operadores de torno mecânico, operadores de inspeção. De um ponto-devista das operações, de outro lado, vários produtos (exemplo: eixos e buchas) aparecem do lado dos trabalhadores e máquinas. Ou seja, os pontos-de-vista de análise são distintos e autônomos, embora interrelacionados.

\section{O Mecanismo da Função de Produção: Elementos Básicos de Análise}

Feita a apresentação da estrutura de produção, proposta por Shingo como uma rede de processos e operaçōes, é preciso identificar os elementos básicos de análise destes processos e operações.

\section{Elementos Básicos para Análise dos Processos}

Todos os aspectos que constituem um processo, fluxo de materiais no tempo e no espaço, podem ser observadas a partir das 4 categorias de análise, abaixo expostas:

- processamento ou trabalho em si significam basicamente a transformação das matérias primas e materiais; como exemplo, pode-se citar: fabricação (usinagem, pintura, etc...), mudanças de qualidade do produto, montagens e desmontagens;

- inspeção : significa basicamente a comparação de materias contra determinado(s) padrão (ões);

- transporte: significa basicamente determinada mudança de posição ou de localização dos materiais;

- estocagem ou espera: significa basicamente os períodos de tempo onde não está ocorrendo nenhum tipo de trabalho, transporte ou inspeção.

O processo de estocagem ou espera está dividido segundo quatro subcategorias de análise qualitativamente distintas: as esperas entre processos (ou mais sucintamente, espera de processo) e as esperas devido ao tamanho dos lotes (ou mais sucintamente, espera dos lotes), a armazenagem de matérias primas e de armazenagem de produtos acabados.

A espera do processo implica que um lote inteiro está em situação de espera, enquanto o(s) lote(s) que se segue está sendo processado, inspecionado, ou transportado. Ou seja, todo o lote está aguardando até o próximo processo ser completado.

A espera do lote tem uma característica completamente diferenciada. Relaciona-se ao fato de que, enquanto uma peça do lote está sendo processada, as demais peças do mesmo lote estão em condições de espera.

As peças que estāo em condiçōes de es- 
pera podem encontrar-se em duas situações genéricas: "peças não processadas" e "peças já processadas". Observa-se que quando refere-se ao processo, ele tanto pode ser o processamento em si (fabricação, montagem, etc...), como nos processos de inspeção e transporte.

Tem-se ainda a armazenagem de matérias-primas e produtos acabados. Estas duas estocagens são fenômenos ligados a fatores externos à fabrica. Os dois fenômenos mais importantes de serem analisados, do pontode-vista interno à empresa, são os estoques entre processos e estocagens dos lotes.

\section{Elementos Básicos para Análise das Operações}

A seguir apresentar-se-á detalhadamente os elementos constitutivos básicos das operações, fluxo dos homens e máquinas no tempo e no espaço, que podem ser reduzidos às categorias de análise (os conteúdos das operaçôes) mostrados abaixo.

1) Preparação, operação de ajustes de pois da operação (operações ligadas ao tempo de preparação: set-up):

Refere-se basicamente a mudança de ferramentas e dispositivos; referem-se às atividades operativas que ocorrem desde que a última peça boa do lote precedente é produzido, até a fabricação da primeira peça boa do lote que se segue; dou seja, referem-se basicamente à logica do tempo de preparação (set-up).

\section{2) Operação principal}

São as funçōes essenciais diretamente ligadas à operações de processamento em si, inspeção, transporte e espera.

A operação pode ser dividida em duas subcategorias: operaçōes essenciais e operações auxiliares.

As operaçöes essenciais constituem-se na execução dos processos de produção em si.

São os pontos da rede onde as operações e os processos encontram-se num dado tempo e espaço. Nestes pontos encontram-se os homens, a máquinas e dispositivos, (sujeito ao trabalho) e os materiais (objeto de trabalho).

\section{Divide-se em:}

operacão essencial de processamento constituem-se na fabricação e montagem de produtos;

operação essencial de inspeção - constituem-se na observação no chão-de-fábrica da qualidade dos produtos;

operação essencial de transporte - constitue-se na mudança de posição dos produtos a nível do chä-de-fábrica;

operacão essencial de estocagem - referese a estocagem de produtos em prateleira, etc...

As operações auxiliares constituem-se na execução de atividades que se encontram imediatamente antes e imediatamente depois da realização das operações essenciais. São atividades operativas que realacionamse diretamente com as operações essenciais, suportando, por assim dizer as mesmas.

\section{Podem ser divididos em:}

operação auxiliar de processamento - refer-se à alimentação e desalimentação das máquinas e linha de montagem; por exemplo, fixar e desatarrachar os produtos das máquinas;

operação auxiliar de inspeção - refere-se às atividades que precedem $\mathrm{e}$ antecedem a operação principal de inspeção. Por exemplo, manipulação de instrumentos, equipamentos e produtos, visando a efetivação da inspeção;

operaçāo auxiliar de transporte - refere-se basicamente aos carregamentos que precedem ao transporte efetivo em si e os descarregamentos que sucedem o transporte efetivo em si, ou seja, operações auxiliares de transporte implicam no carregamento e descarregamento dos equipamentos de transporte;

operacāo auxiliar de estocagem - referese basicamente às atividades de colocação e retirada dos produtos dos locais específicos 
de estocagem, tais como: prateleiras, etc...

3) Folgas não ligadas ao pessoal

São folgas, ou seja, tempos onde os operadores não estão realizando as atividades fim. As causas destas folgas encontram-se em operaçōes irregulares (não previstas) que ocorrem de forma inesperada na produção.

Ou seja, são folgas cujas causas fundamentais não estão ligadas à ação direta das pessoas.

Podem ser divididas em duas subcategorias gerais; folgas na operação e folgas entre operações ${ }^{2}$

As folgas na operação referem-se a trabalhos irregulares que ocorrem e são ligados diretamente à operação. Como exemplo desta folga não ligadas ao pessoal, pode-se citar: lubrificação, renovação de ferramentas, recolocação de ferramentas danificadas, limpeza de "chips" utilizados na indústria eletrônịca.

As folgas entre operaçōes são trabalhos irregulares que ocorrem entre operaçōes consecutivas. Como exemplo, pode-se citar: espera para suprimento de materiais, recolocação de produtos em pallets.

Enquanto as folgas nas operaçōes ligamse às operações de processamento em si, inspeção, transporte, e espera, as folgas entre operações ligam-se a problemas de sincronização entre diferentes operaçōes (processamento em si, inspeção, transporte e espera).

\section{4) Folgas ligadas ao pessoal}

As folgas ligadas ao pessoal caracterizam-se por trabalhos irregulares ligados diretamente à pessoas e não conectadas com as máquinas e operações.

As folgas ligadas ao pessoal podem ser divididas em duas subcategorias gerais: as folgas por fagiga e as folgas físicas (higiênicas);
As folgas por fadiga caracterizam-se em tempo de não atividade produtiva dos operadores relacionados à necessidade de recuperação das fadigas de origem física ou mental;

As folgas físicas ou higiênicas caracterizam-se por um tempo de não atividade produtiva relacionada com a satisfação de suas necessidades fisiológicas, tais como: beber água, ir ao banheiro, etc...

\section{Críticas Gerais à Lógica de Análise Hegemônica na Engenharia Industrial a Partir da Ótica do Mecanismo da Função de Produção: Algumas Consideraçōes}

Quais são as melhorias mais importantes: as associadas à função processo ou à função operação?

Após uma análise da estrutura da produção a partir da ótica do mecanismo da função de produção, uma pergunta parece necessária:

quais são as melhorias mais relevantes na estrutura de produção: aquelas ligadas aos dos processos, aquela associada às operações ou estas melhorias são indiferentes quanto ao seu grau de importância?

Esta discussão é particularmente importante na medida em que pretende-se analisar as raizes centrais da constituição do mecanismo da função de produção.

A resposta proposta por Shigeo Shingo é pragmática: as principais melhorias estāo necessariamente assoicadas ao processo.

Assim Shigeo Shingo (1986) enuncia que: "é função processo, em verdade, que permite atingir as principais metas de produção, enquanto as operaçōes desempenham um papel suplementar".

2 Nos textos escritos por Shigeo Shingo aparecem duas expressões em inglês para designar golgas da operação que são "Job Allowance"e "Operation Allowance" já a folga entre operações é chamada por Shigeo Shingo de "Works- 
Ainda Shigeo Shingo (1986) atribui as diferenças básicas existentes entre os princípios de produção ocidentais e japonesas, à compreensão no nível mais básico, do que significa a estrutura de produção. $O$ pontode-vista de Shingo (1988) é que a "produção contitui uma rede de processos e operaçōes, fenômenos que podem ser colocados ao longo de eixos que se interseccionam. $\mathrm{Na}$ melhoria de produção deve ser dada alta prioridade aos fenômenos ligados ao processo

De acordo com Shingo, sem a compreensão do significado do mecanismo da função de produção e da necessáriua priorização das melhorias do processo é impossível compreender o significado dos sistemas de produção em geral, e do Sistema Toyota de Produção, em particular.

Assim Shingo (1986) afirma que: "O Sistema Toyota de Produção representa uma tentativa pioneira desta nova filosofia de produção, mas nenhuma inovação fundamental na produção pode vir meramente pela imitação dos aspectos superficiais do Sistema Toyota"4

Observe aqui que outros modelos de produção podem ser construídos a partir do mecanismo da função de produção e da lógica de priorização das melhorias no processo, sendo o Sistema Toyota de produção a primeira tentativa intencional bem sucedida neste sentido.

Para melhor elucidar essa discussão, a seguir propōe-se uma série de exemplos que discutem a relação entre as melhorias no processo e nas operações.

a) Um exemplo clássico consiste na diferenciação entre melhorias no transporte e melhoria do trabalho de transporte

Suponha a necessidade de transportar um determinado lote entre dois centros de trabalho C1 e C2 que estão localizados a 100 metros de distância. $\mathrm{O}$ transporte atualmente é feito de forma manual. Pergunta-se; a melhoria no processo de transporte tem o mesmo significado na operação de transpor- te? Ocorreriam melhorias profundas caso um consultor propusesse a troca do transporte manual por um transporte via, por exemplo, uma correia transportadora?

Aqui torna-se fácil observar a diferença entre a lógica de melhoria no processo de transporte e melhoria na operação de transporte.

Se for aceita a proposta do consultor, na verdade está ocorrendo uma melhoria na operação de transporte dado que houve uma mudança no equipamento. Porém, do ponto-de-vista do fluxo do material, (processo) continua havendo movimentação do Centro de trabalho $\mathrm{C} 1$ e $\mathrm{C} 2$ que encontramse a 100 metros de distância. Portanto, conclui-se, de forma lógica, que não ocorreu uma melhoria do ponto-de-vista do processo de transporte.

A radical melhoria no processo de transporte ocorreria caso não houvesse a necessidade do transporte do material entre os centros de trabalho C1 e C2.

Isto poderá ser possível, por exemplo, aplicando técnicas do tipo Tecnologia de Grupo para melhoria do Lay-out. Ou seja, com o uso da correia transportadora observou-se uma melhoria na operação de transporte, porém, o processo de transporte não foi significativamente alterado. Porém, quanto altera-se radicalmente o processo, as operaçōes de transporte (no caso a correia transportadora) podem tornar-se simplesmente desnecessárias.

Como lógica global pode-se dizer que uma atuação sistêmica quanto a questão do transporte interno de materiais seria:

1.a) projetar melhorias no processo de transporte visando eliminá-lo ou minimizálo; neste caso ter-se-á as grandes melhorias no transporte interno em si.

2.a) uma vez projetado e executado a melhoria no processo de transporte, cabe otimizar as ações de transporte interno via melhoria reais nas operaçôes de transporte restantes.

\footnotetext{
${ }^{3} \mathrm{O}$ grifo é feito por Shigeo Shingo

${ }^{4} \mathrm{O}$ grifo é feito pelo autor deste trabalho.
} 
b) Há relação de prioridade possível entre a padronização de produtos e o ataque a questão dos tempos de preparação (set-up time)?

Tomemos uma indústria que fabrica móveis do tipo dormitórios (camas, guardaroupas, escrivaninhas). No caso de guardaroupas, por exemplo, produz-se móveis modulados com diferentes alturas e larguras para cada tipo de produto. Observa-se, também, que os tempos de preparação são elevados na produção, bem como ocorre muita necessidade de trocas para a fabricação destes diferentes lotes.

O gerente de produção propōe um significativo esforço na área de redução dostempos de preparação para aumentar a capacidade real das máquinas gargalo e para ganhar flexibilidade de respostas a demanda do mercado.

O responsável de pesquisa e desenvolvimento propōe o ataque à padronização dos produtos.

Os recursos financeiros disponíveis permitem que os dois problemas sejam abordados simultaneamente.

Seria lógico, do ponto-de-vista econômico efetivar estes esforços simultaneamente?

Novamente, as noções da funçāo processo e da função operação permitem uma abordagem lógica do problema.

A padronização influencia diretamente no fluco de materiais no chāo-da-fábrica. Trata-se de um problema que atinge diretamente a problemática do processo.

Já a redução dos tempos de preparação relacioam-se mais diretamente com a problemática da operação.

Observa-se que efetiva-se a padronização (análise de processo) das alturas e larguras dos guarda-roupas, imediatamente o fluxo de materiais na fábrica se simplifica e muitas preparaçōes, anteriormente necessárias, simplesmente tornam-se desnecessárias.

Ou seja, do ponto-de-vista econômico observa-se grandes melhorias quando do ataque ao procedimento de padronização, dado que ele interfere diretamente na função processo.

Como ressalva pode-se dizer que projetos-piloto na área de redução de tempos de preparação podem ser executados paralelamente, porque representam uma seqüência natuaral de melhoria no sistema produtivo.

Caso o ataque aos tempos de preparação seja priorizado e feito massivamente, observa-se que uma parte do trabalho mostrar-seá desnecessária quando a padronização dos produtos for levada a efeito.

c) exemplos de influências na função processo em virtude da padronização dada a melhoria na funça operação.

Shingo (1986) exemplifica três casos típicos de preocupação com melhorar o lado da função operação, sem uma real preocupaçāo com a função processo.

I) Caso na lógica de agrupamento de máquinas na fábrica priorizando-se somente a função operação, as máquinas serão agrupadas por grupos similares (lay-out funcional). Porém em termos da lógica de função processo isto acarretará um aumento da necessidade de transporţe o que certamente irá aumentar os custos 5 .

II) Esforços localizados para levar todas máquinas ao limite de suas capacidades de produção. Isto do ponto-de-vista da lógica da função processo irá somente gerar desbalanceamente entre as máquinas. Por conseqüência as esperas entre os processos irá aumentar com a elevação dos custos associados ${ }^{\text {. }}$

\footnotetext{
5 Além disso muitos outros problemas, além do transporte devem ser considerados. Aumento do tempo de atravessamento na produção ("lead-time") incremento do nível de defeitos e retrabalhos, etc...

${ }^{6}$ Ou seja, através da análise do Mecanismo da Função de Produção chegar-se-á as mesmas conslusões propostas por Elly Goldratt (GOLDRATT, 1992) no que concerne a teoria das restriçōes. assim, pode-se facilmente concluir que o balanceamento no processo é o fundamental dada que a somados ótimos locais do sistema (otimizar, por exemplo, as capacidades individuais das máquinas) é diferente do ótimo global do sistema.
} 
III) A condução da otimização da função operação, no que concerne a produção de grandes lotes de produção para minimizar o tempo perdido com tempos de preparação (set-up's) excessivos, levará a um incremento do inventário.

A partir dos exemplos acima discutidos torna-se claro que uma vez que os sistemas produtivos sejam vistos como rede de processos e operaçōes, deve-se dar uma ênfase prioritária às melhorias da função processo, complementando estas melhorias através da função operação.

Como conclusão destes itens, algumas observações feitas por Shingo (1986) são essenciais.

Em primeiro lugar é preciso observar que é necessário "pensar os processos como operações que servem os clientes, e operações como ações executadas para obter eficiência das partes" (SHINGO, 1986). Isto exige uma necessidade permanente de harmonizar as açōes no campo do processo e da operação. No entanto, sempre deve-se ter em mente que "é a função processo, de fato, que permite alcançar os objetivos principais da produção, enquanto as operações desempenham um papel suplementar" (SHINGO, 1986).

Assim, é possivel que, mesmo que as operações localizadamente possam apresentar resultados excepcionais, como por exemplo, a compra de algumas máquinas de concepção muito modernas e eficazes, o sistema produtivo em sua globalidade pode não estar otimizado "caso as funções processo estejam inadequadas" (SHINGO, 1986).

Ou seja, se houverem incorreções na organização dos processos, produtos defeituosos e com custos elevados serão produzidos, não interessando o grau de perfeição com que as operaçōes individualmente estejam sendo efetivados (SHINGO, 1986).

Em segundo lugar, é preciso modificar alguns aspectos da cultura técnica dos engenheiros e supervisores, no que concerne a postura e visualização das necessidades de priorização entre as funções processo e operação.
Fica claro, a partir dos exemplos expostos arteriormente, que existe uma precedência da função processo sobre a função operação na melhoria dos sistemas produtivos.

No entanto, Shingo (1986) postula que no mundo real as atividades produtivas que são mais comumente observadas relacionam-se a função operação e que, de forma geral, as funçōes relacionadas ao processo deixam uma impressão bastante frágil no pessoal ligado à fábrica. Isto porque a lógica da função processo fica escondida pelas operaçōes, que por sua vez são muito mais explícitas.

Assim, existe uma necessidade premente de envitar esforços no sentido de chegar a uma cultura técnica de Engenharia Industrial que faça vir à tona a compreensão da importância da função processo na melhoria dos sistemas produtivos.

\section{Críticas à Visāo Hegemônica nos EUA e Europa Sobre os Conceitos de Processo e Operação.}

Um tópico muito importante para a compreensão do Mecanismo da Função de Produçāo consite em confrontar os conceitos apresentados neste trabalho, com os conceitos usualmente aceitos no ocidente (EUA e Europa) sobre o significado do conceito de processo e da operação.

Em geral, no ocidente os conceitos de processo e operação são imaginados como pertencentes a um mesmo eixo de análise.

Dentro desta concepção linear, qual seria a diferenciação entre estes dois conceitos?

A idéia de operação estaria diretamente relacionada com estudos feitos a partir de pequenas unidades de análise.

Já os processos são visualizados a partir de grandes unidades de análises.

Assim os processos seriam constituídos, em sua essência, de um grupo de operaçōes. Ou seja, o somatório de várias operações (unidades de análise memorial) contituiriam 
um dado processo (unidade de análise agregada).

Deriva, diretamente, deste tipo de raciocínio que, uma vez obtidas as melhorias nas operações, (nível micro) automaticamente está obtendo-se melhorias em um dado processo do qual faz parte este conjunto de operações.

Dentro desta visão, os sistemas de produção são vistos a partir de uma ótica linear onde não existem diferenciação de fundo entre os conceitos de operaçōes e processos.

Shingo (1988) ainda ressalta que também no Japão certos livros de Engenharia Industrial copiaram as concepções ocidentais sobre os conceitos de operação e processo.

Neste ponto, observa-se uma grande diferenciação do pensamento de Shingo relativamente aos ocidentais.

Isto porque na ótica hegemônica de análise nos EUA a Europa năo faz-se a necessária separação na análise do processo e das operaçōes. Estas duas análises são vistas numa relação de dependência, onde o processo é uma somatória de operaçōes.

Na Visão de Shingo, estas duas análises devem ser feitas de forma independente embora necessariamente interrelacionadas.

A razão é óbvia. Enquanto na análise da função processo acompanha-se o objeto de trabalho (materiais) no tempo e no espaço, na análise da funçāo operaçāo acompanham-se o sujeito de trabalho (homens e equipamentos) no tempo e no espaço.

Portanto, a diferenciaçāo entre operação e processo não apresenta nenhum relacionamento com o tamanho da unidade de análise (grande ou pequenas unidades de análise).

Assim, é preciso observar estas diferenças caso deseje-se entender em profundidade as bases de construção do sistema Toyota de produção.

Shingo é categórico e amplo quando afirma que a distinção clara entre os conceitos de função processo e função operação constituem-se em "um ponto chave para o desenvolvimento de novos sistemas produtivos" (SHINGO, 1988).

Finalmente, cabe questionar as razōes porque durante longo tempo deu-se priorização à análise das operações na literatura de Engenharia Industrial Ocidental. Shingo (1988) propõe as seguintes explicações gerais:

a) as operações são executadas em lugares específicos e bem determinados de tal forma que os trabalhadores, supervisores, gerentes intermediários e a alta gerência tem acesso direto e visual às mesmas; já os processos envolvem a movimentação de materiais e produtos semi-acabados por toda a fábrica, tornando difícil a avaliação mais direta da mesma;

b) uma razão mais importante é a aceitação, sem questionamento, da tese segundo a qual o processo constitui-se de uma unidade de análise grande, enquanto as operações seriam constituídas de unidades de análises pequenas; isto leva a assumir-se erroneamente que, melhorando as operaçōes, automaticamente os processos serão melhorados.

Agrava-se esta problemática na medida em que raros acadêmicos e gerentes no ocidente reconhecem que na verdade os sistemas produtivos constituem-se uma rede de operações e processos. Mais, ainda, poucos reconhecem que a análise de função processo é essencial para as melhorias, sendo suplementada pelas melhorias na função.

\section{Exemplos de Utilização do MFP para a Compreensão de Alguns Pontos do Sistema Toyota de Produção}

A seguir apresentar-se-ão dois exemplos da utilização do MFP para a compreensão de alguns pontos constitutivos básicos do sistema Toyota de Produção.

1) O MFP e o conceito de Automação e Pokayoke

"É muito bem compreendida no Sistema Toyota de Produção a separação entre 
máquina e homem. Se estes pensamentos não são perfeitamente entendidos, uma compreensão correta do sistema Toyota de Produçāo não pode ser conseguida"

(SHINGO, 1981)

Em uma dada fábrica de alto desempenho que começa a operar logo após o pressionar de uma dada chave... Se algo acontece, por exemplo, a ferramenta macho quebra e começam a aparecer defeitos que podem transformar-se rapidamente em dezenas ou mesmo centenas de produtos com defeito. como pode-se prevenir isto?

A soluçāo tradicional em fábrica que não adotam modernos sistemas produtivos consiste em designar um operário específico para cada máquina com o intuito exlusivo de cuidar a possibilidade eventual de ocorrência do defeito e, portanto, de agir localmente para parar a máquina e impedir o alastramento da produção de artigos defeitusosos.

Se generalizarmos este tipo de solução para toda a fábrica, ter-se-á, incansavelmente, a idéia de que a cada máquina está associado, no mínimo, um operador.

Neste sentido pode-se dizer, a partir da lógica histórica de Taylor - um homem/um posto/uma tarefa, que existe uma relação inseparável entre a máquina e o homem.

Vamos observar a problemática a partir da ótica do MFP.

Do ponto-de-vista da análise da função processo observa-se que a eventual garantia de que o fluxo de materiais dar-se-á qualitativamente e quantitativamente de forma fluente é dada a partir da utilização de um homem permanentemente vigiando cada máquina.

Porém, caso os operadores afastem-se das máquinas, ou mesmo cometa erros em sua observação, duas das 7 perdas conceituais propostas por Shingo e Ohno imediatamente poderão aparecer.

1) As perdas por superprodução na medida em que sejam produzidas um número de peças maior do que a plenejada.

2) As perdas por fabricação de produtos defeituosos na medida em que alguma coisa não assinalável (especial) surja no processo.

Do ponto de vista da análise da função operaçấo observar-se-á que cada trabalhador ficará 8 horas diárias de trabalho envolvido diretamente com uma mesma máquina, ora observando seu funcionamento, ora envolvido em sua preparação, ora alimentado as máquinas, etc...

Ainda observar-se-á que durante o tempo de execução da operação, o trabalhador ficará simplesmente observando a máquina funcionar.

Isto pode ser analiticamente considerado como uma perda por espera.

Ainda é preciso observar uma condição de contorno do problema. No caso da Toyota dos anos 70, observava-se ainda que a média do custo horário da mão-de-obra era de 3 a 5 vezes maior do que o custo horádio das máquinas.

Assim, combinando na fotografia retirada da análise do Mecanismo da Função de Produção, com a lógica econômica dos custos e das perdas, torna-se evidente que a lógica Taylorista, de associar a cada posto de trabalho um homem, torna-se bastante dispendioso do ponto-de-vista da Toyota.

Em termos microeconômicos a questão torna-se: como aumentar a taxa de ocupação da mão-de-obra?

Dentro deste contexto Ohno e Shingo partiram para o equacionamento das melhorias do projeto do sistema produtivo que poderiam minimizar as perdas por superprodução, fabricação de produtos defeituosos e por espera.

A pergunta central era: como criar condiçōes no Sistema Produtivo para permitir a separação entre a máquina e o homem no sentido de melhor aproveitar o salário horário pago acoplando a isto a eliminaçāo da produção em massa de defeitos e a superprodução de peças?

Obviamente a resposta a esta questão não foi imediata, porém, foi desenvolvida historicamente. Isto implicou inclusive com 
a retomada de práticas consagradas anteriormente em outras fábricas japonesas que não a automobilística.

Ohno (1988) perguntou-se ! "Por que uma pessoa na Toyota Motor Company opera apenas uma máquina enquanto na Toyota Têxtilorigem histórica da Toyota, uma mulher é capaz de cuidar de 40 a 50 teares automatizados?

E Ohno percebe que uma razão inicial é que as máquinas na Toyota automobilística não estavam preparadas em seu evidente projeto do sistema produtivo para parar quando a operação se completasse.

Surge, então, a idéia de elaborar teoricamente uma prática inicalizada e criada na Toyota Têxtil por Toyota Sakiichi que consistia em criar dispositivos que permitissem a parada automática das máquinas caso a quantidade produzida fosse alcançada, ou algum tipo de anormalidade fosse detectada.

É criada, a partir da prática industrial da Toyota Têxtil, a noção teórica de Automação.

A automação consiste em facultar ao operador ou à máquina a "autonomia" de interromper a operaçāo sempre que ocorrer alguma situação anormal na máquina ou quando a quantidade planejada de produção for atingida.

A operacionalização do conceito de aultomação segue vários caminhos: um destes caminhos operacionais é a construçāo de dispositivos do tipo "Poka-Yoke" ou a prova de falhas.

O Poka-Yoke pode ser conceituada como um sistema composto de dispositivos (um ou mais) que são capazes de detectar a ocorrência de anormalidades (falhas ou defeitos) e/ou de identificar quando a quanti- dade de peças planejada já foi produzida.

Neste sentido constitue-se, na prática, em um sistema inspeção $100 \%$, que proporciona uma imediata retroalimentação aos operadores e supervisores quando da ocorrência de anormalidades ou de alcance da produção desejada.

Assim, quando as máquinas dispõem de dispositivos do tipo Poka-Yoke, uma vez alimentada a máquina é posta em operação, o operador pode dirigir-se a outras máquinas para realizar outras tarefas, dado que existe segurança completa quando a detecção imediata e "autônoma" de anormalidades e do alcance da produção desejada.

$\mathrm{Na}$ Toyota isto acarretou:

1) diminuição dos tempos de espera dos trabalhadores com conseqüênte redução/eliminação da chamada perda por espera, como conseqüência, incrementou-se em muito a taxa de ocupação da mão-de-obra;

2) eliminação ou redução a um valor mínimo das perdas por superprodução e das perdas por superprodução e das perdas por fabricação de produtos defeituosos;

3) abrir portas concretamente para introdução do conceito de multifuncionalidade na medida em que possibilitou a separação entre a máquina e o homem, neste sentido, uma análise da função operaçāo após a introdução do Poka-Yoke mostra um incremento substancial do aproveitamento do tempo produtivo dos trabalhadores ${ }^{8}$

Um outro aspecto importante é que os sistemas do tipo Poka-Yoke propiciam a redução da espera dos trabalhadores.

Isto ocorre na medida em que a máquina pára quando um defeito é detectado. Neste sentido observa-se que somente peças no nível especificado de qualidade é enviado

${ }^{7}$ A conceituação de "Poka-Yoke", bem como suas ligaçōes com a política da produção com Zero-defeitos e suas práticas operacionais, é amplamente discutida por Shingo (1986) em seu livro "Zero Quality Control: Source Inspecion and The Poka-Yoke System"

${ }^{8}$ Na verdade o conceito de automaçāo em geral, e dos sistemas Poka-Yoke em particular, pode ser analisado como uma proposta do capital visando incrementar aprodutividade via intensificação do trabalho. Ou seja, com as mesmas máquinas e trabalhadores, aumentar a produtividade através de procedimento de reorganização da produção e 
para as próximas máquinas. Além disso, a máquina também é programada para parar automaticamente quando a quantidade requerida ou a operação é completada. Desta forma, uma dada máquina fornecerá às próximas máquinas ou postos de trabalhos peças nas quantidades especificadas. Isto permitirá a execução da produção no tempo certo, ou seja, segundo a lógica JIT (MODEN, 1981).

Caso as peças não cheguem na qualidade e na quantidade certa, as próximas operações de processamento não podem ser efetuadas, portanto, os operadores terão um maior tempo de espera. Isto levará ao incremento das perdas por espera. Neste sentido a produção JIT torna-ş̧ praticamente impossível de ser efetivada

Uma análise das funções operação e processo identificará claramente estes fatos.

O MFP e o conceito de 7 perdas proposto por Ohno e Shingo

Shingo (1988) propõe que sejam construídas melhorias na produção a partir da seguinte lógica básica:

$\left.1^{9}\right)$ conceitos básicos de análise dos sistemas produtivos;

$2^{2}$ ) construção de sistemas a partir dos conceitos básicos; ma.

$\left.3^{2}\right)$ técnicas para a implantação do siste-

Dentro deste contexto, a lógica de análise do Mecanismo de Produção, do conceito de perdas em geral e de 7 perdas em particular e as condiçōes de contorno econômico se interrelacionam para a geração dos conceitos básicos que levarão à definição dos sistemas de produção em geral e do Sistema Toyota de Produção em particular.

Porém, como estabelece-se este relacionamento?
Neste ponto é importante diferenciar os planos onde situam-se estes três elementos: Mecanismos da Função de Produção, perdas e condições de contorno sócio-econômicos.

O Mecanismo da Função de Produção é uma ferramenta de análise de sistemas Produtivos. Utiliza-se dos métodos de análise da função processo e da função operação. Neste sentido, é independente das condições econômicas que cercam o Sistema Produtivo em Análise. Em outros palavras, é o elementos "mais invariante" na discussão aqui feita.

O Mecanismo da Função de Produção permite uma análise técnica dos sistemas de produção. Portanto, possibilita comprar sistemas de produção entre si.

$O$ conceito de perdas e de 7 perdas surge a partir da lógica de reduçōes de custos. Neste sentido, está preso diretamente à questão das necessidades de redução de custos na empresa em função de suas necessidades no merdado. Portanto, estão intimamente relacionados a uma dada realidade econômica e social.

Esta realidade econômica e social representa o terceiro plano da discussāo e referese às condições de contorno do sistema produtivo.

Por exemplo, no Japão o custo horário da mão-de-obra é de 3 a 5 vezes superior ao custo-horário das máquinas, enquanto no Brasil o custo-horário da mão-de-obra é menor do que o custo-horário das máquinas.

Outro exemplo interessante refere-se às preocupações econômicas e sociais dentro do dito socialismo real. Neste caso parte-se da necessidade social de usar intensivamente o recurso mão-de-obra visando manter um alto nível de emprego. Obviamente, estas condiçōes de contorno são diferentes da racionalidade econômica do tipo capitalista.

\footnotetext{
9 A análise de um caso de implantação do JIT no Brasil, mostra claramente que a inobservância dos aspectos aqui descritos torna muito difícil a implantação do JIT, dado que ela é absolutamente sustentada pelo conceito de automação e sistemas do tipo Poka-Yoke. Tem-se, a nível da produção, a lógica da inspeçāo $100 \%$ nos postos de trabalho.
} 
Dentro deste contexto geral, a geração dos conceitos básicos para construção do Sistema Toyota de Produção devem ser compreendidos a partir desta lógica de relação entre o Mecanismo da Função de Produção, o conceito de 7 perdas e as condições de contorno sócio econômicos.

No caso específico do STP isto pode ser visto na figura 2 a seguir:
O objeto de trabalho pode ser o couro em uma indústria de calçados, o aço em uma empresa metal-mecânico, o próprio ônibus em uma empresa de ônibus, algum tipo de processo de lei em uma Assembléia, etc...Porém, embora exista uma enorme diversificação do objeto de trabalho, a lógica da função processo permanecerá incólume.

A função operação, por sua vez, também contará genericamente com as preparaçōes,

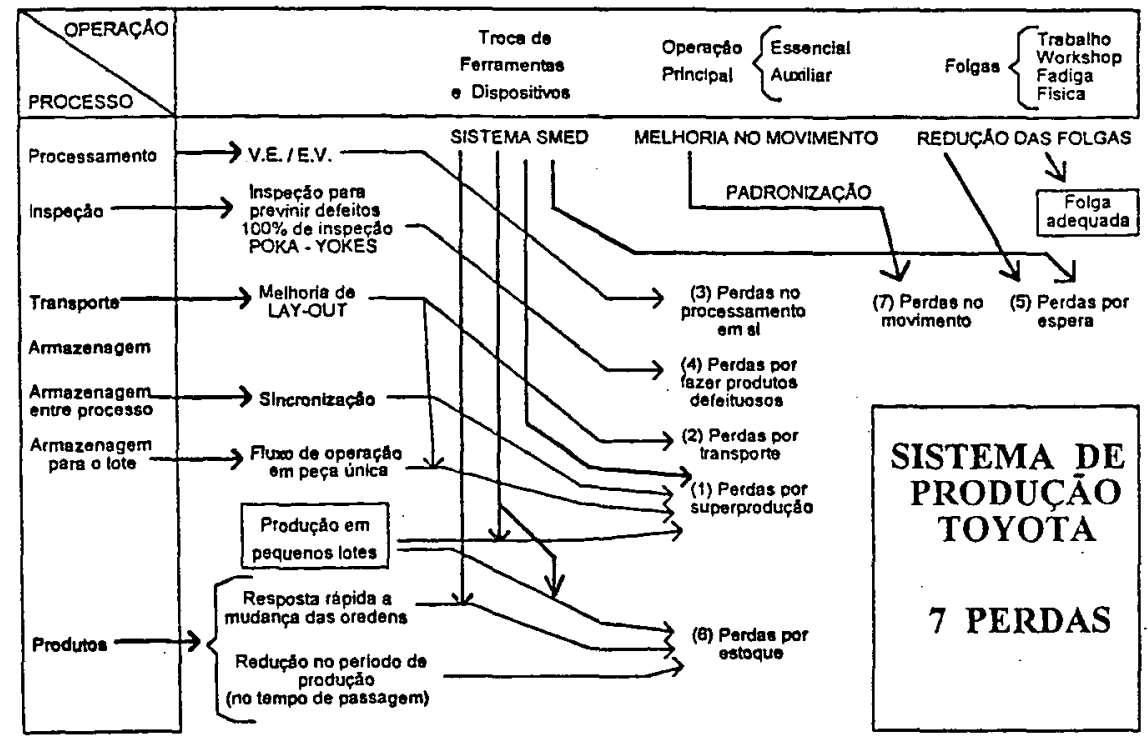

Figura 2 - Sistema de Produção Toyota - 7 perdas (Shingo)

\section{Conclusão}

A lógica básica de construção teórica do Mecanismo da Função de Produção é absolutamente geral para a geração de sistemas de produção.

$\mathrm{Na}$ verdade em todos os sistemas de produçāo, seja ele fábrica em geral (sapatos, metal-mecânica, móveis, etc...), uma empresa de ônibus ou uma secretaria de governo, nós teremos presentes todos os elementos básicos do processo. Isto significa que o objeto de trabalho estará alternadamente sendo transportado, ou estará sendo verificado a ocorrência de defeitos (inspeção), ou estará em alguma forma de processamento, ou simplesmente estará estocado. operaçōes principal e secundária, folgas não ligadas ao pessoal. $O$ conteúdo das operaçốes pode ser bastante diversificado, como nos casos dos processos, porém sua forma geral é comum.

Por outro lado, é preciso deixar claro que a lógica de melhorias propostas por Shigeo Shingo, via Mecanismo da Função de Produção, não refere-se a técnincas de manufatura, mas sim a melhorias concretas em sistemas de produção. Ou seja, perguntas tais como: como fazer para curtir o couro? como fazer para melhorar uma dada usinagem? como fabricar um dado móvel? são questōes e problemas de manufatura.

Estas, por sua vez, do ponto-de-vista téc- 
nico, não podem ser generalizadas. No entanto, a lógica do Mecanismo da Função de Produção trata da problemática, esta sim generalizável, da obtenção de melhorias de sistemas de produção.

Assim sendo, para o estabelecimento de uma lógica de melhoria em Sistemas Produtivos é essencial partir de um forte ferramental analítico. O Mecanismo da Função de Produção é um ferramental analítico robusto que permite analisar em profundidade a produção a partir de uma lógica de redes de processos e operações.

O fato de Shigeo Shing atuar diretamente ligado, em sua tragetória de consultoria, à problemática industrial, não deve obscurecer o fato de sua base conceitual via MFP ser geral.

Neste sentido, abrem-se importantes oportunidades de investigação no sentido da montagem de sistemas de melhoria de produção adaptáveis a área de serviços, tendo como elemento de base o próprio Mecanismo da Funçāo de Produçāo - uma rede genérica de processos e operação.

A análise do Mecanismo da Função de Produção permite, em tese, a construção do embasamento para o debate sobre pontos tão amplos quanto:

a) compreender a lógica de montagem do Sistema Toyota de Produçáo;

b) esclarecer um método de análise da produção que possibilita a construção de outros sistemas de produção alternativos ou complementares ao Sistema Toyota, caso outras condiçōes de contorno econômico e sociais sejam propostas;

c) a análise sistemática de outros modelos de produção competitivos com o japonês como por exemplo, o modelo Sueco;

d) a critica social do ponto de vista dos trabalhadores, dos alicerces sócio-econômicos de construção do Sistema Toyota, que tem o MFP como um dos pilares das suas bases conceituais;

e) uma análise sistemática dos conceitos de perdas propostos por Taylor, Ford, Taii- chi Ohno e Shigeo Shingo.

Finalmente, como última conclusão, pode-se afirmar que é preciso, na análise de sistemas de produção, deixar claro a necessidade de hierarquizar as açōes de melhoria a partir da lógica da função operação. Isto é essencial para que se possa criar uma cultura técnica de melhorias fortemente enraizada na visualização da estrutura de produção enquanto uma rede.

\section{Referências Bibliográficas}

GOLDRATT, Eliahu. M \& COX, Jeff A Meta, Editora do IMAN (Educador), São Paulo, 1992.

OHNO, Taiichi. Toyota Production System. Productivity Press. Cambridge, Massachussets and Norwalk, Connecticut, 1988.

SEPEHRI, Mehram. Just-In-Time Not Just in Japan: Case studies of americam pioneers in JIT implementation. The Library of American Production-APICAS Education and Research Foundation, 1986.

SHINGO, Shigeo. Study of Toyota Production System, from Industrial Engineering View Ponint, Japan Management Association, 3-1-22, Shiha-Park Minatu-Hu, Tokyo, Japan, 1981.

SHINGO, Shigeo. A Revolution in Manufacturing - The SMED System, Productivity Press, Cambridge, Massachussets, Norwalk, Connecticut, 1985.

SHINGO, Shigeo. Zero Quality Control; Source Inspection and the Poka-Yoke System. Productivity Press, Cambridge, Massachussets and Norwalk, Connecticut, 1986.

SHINGO, Shigeo. The Saying of Shigeo Shingo. Productivity Press, Cambridge, Massachussets and Norwlk, Conecticut, 1987.

SHINGO, Shigeo. Non-Stock Production: The Shingo, System for Continuos Improvement. Productivity Press, 1988. 